\title{
On the Evaluation of Power Quality Indices in Distribution Systems with Dispersed Generation
}

\author{
A. Bracale ${ }^{1}$, G. Carpinelli ${ }^{2}$, A. Di Fazio ${ }^{3}$ and D. Proto ${ }^{2}$ \\ ${ }^{1}$ Department for Technologies \\ University of Napoli Parthenope \\ Centro Direzionale di Napoli Isola C/4 80143, Napoli (Italy) \\ Phone number:+0039 0815476757, e-mail: antonio.bracale@uniparthenope.it \\ ${ }^{2}$ Department of Electrical Engineering \\ University of Napoli Federico II \\ Via Claudio, 21 80125, Napoli (Italy) \\ Phone number:+0039 0817683211, e-mail: guido.carpinelli@unina.it, danproto@unina.it \\ ${ }^{3}$ Department of Industrial Engineering \\ University of Cassino \\ Via Di Biasio, 43 03043, Cassino (Italy) \\ Phone number:+0039 07762994366, e-mail: a.difazio@unicas.it
}

\begin{abstract}
The increasing penetration of dispersed generation (DG) influences the power quality (PQ) levels in the distribution networks. Then, an accurate assessment of PQ disturbances in presence of DG is needed and adequate probabilistic indices should be adopted to properly quantify the random nature of the disturbances. In this paper, a tool for the calculation of slow voltage variations, waveform distortions, unbalances, voltage fluctuations and voltage sag probabilistic indices has been developed by using ${ }^{\circledR}$ DigSilent Power Factory software. Numerical applications are performed on a 120-bus distribution network whose DG units are wind generators and gas turbine units.
\end{abstract}

\section{Key words}

Power Quality, Distribution systems, Dispersed Generation, Site Indices, System Indices.

\section{Introduction}

The development of small-scale generation technologies, the need for more flexible electrical systems as well as the deregulation in electric power markets have led Dispersed Generation (DG) to play a significant role on the future development of distribution systems [1].

The growing presence of DG leads to a number of advantages. In fact, being DG located close to the loads, both losses and voltage drops are reduced; in addition, DG can postpone utility investment for distribution networks. Finally, the reduced size of DG units results in low financial risks.

On the other hand, DG can introduce a number of unusual effects, such as bi-directional power flows and an increase of fault current levels.
In addition, an increase of DG penetration can also have a significant impact on the Power Quality (PQ) of the distribution networks. Since DG can reduce or improve the PQ levels, different aspects should be taken into account. In particular, large current variations during DG connection or disconnection can lead to significant voltage transients. The cyclic variation of DG power output can cause voltage fluctuations. The changes of DG active and reactive power and the presence of singlephase domestic generators can lead to long-duration voltage variations and unbalances, respectively. The increasing values of fault currents modify the voltage sag characteristics. Finally, the waveform distortion levels are influenced in a different way according to the type of DG connection to the grid: direct connection or by power electronic interfaces.

DG can also improve PQ levels, mainly as a consequence of the increase of short circuit power and of advanced controls of PWM converters.

Then, in the field of studies related to the modern distribution networks, the assessment of Power Quality levels has become an important issue and several indices have been adopted to quantify the PQ levels in distribution systems with DG. Traditional indices have been applied; both probabilistic "site indices" and "system indices" have been used to quantify the random nature of the disturbances. Site indices refer to a single customer point of common coupling whereas system indices are related to the utility's entire distribution system or to a segment of it [2-3]. More recently, new PQ indices have been proposed to properly evidence the DG impact: these indices quantify the variation of PQ levels due to the DG presence [4]. 
In this paper, slow voltage variations, waveform distortion, unbalances, voltage fluctuations and voltage sag disturbances are considered and both traditional and new indices are applied to quantify the PQ levels in an actual distribution system with DG. In particular, a tool for the calculation of the indices is developed by using ${ }^{\circledR}$ DigSilent Power Factory software and applied to a medium voltage 120-bus distribution network with wind generators and gas turbine units. The traditional uncertainties due to time variations of linear and non linear load demands, of network configurations as well as of wind speed are taken into account. The uncertainties introduced by the energy available from wind is also considered.

\section{Some Indices for Evaluation of DG Impact on PQ}

The problem of the assessment of DG influence on Power Quality levels in a distribution system with DG can be solved by using both traditional and new indices.

\section{A. Traditional Indices}

In this paper, slow voltage variations, waveform distortions, unbalances, voltage fluctuations and voltage sag disturbances are taken into account and the following traditional indices have been considered.

\section{1) Slow voltage variations}

The slow voltage variations are usually quantified by calculation of the RMS value of the supply voltage and the 95 percentile over one week of 10-minute mean RMS values is considered as site index.

The following system indices are considered:

- the percentage of sites that exceeds the objectives in the reporting period;

- the average or median value of the site indices;

- the value of the site index not exceeded for a fixed percentage (90, 95, or $99 \%$ ) of sites; the percentage of sites can be a matter of agreement between the system operator and the regulator.

\section{2) Waveform distortions}

The following site indices are considered:

- the 95 percentile of the voltage harmonic amplitude $\left(\mathrm{V}_{95}^{\mathrm{h}}\right)$;

- the 95 percentile of the Voltage Total Harmonic Distortion $\left(\mathrm{THDV}_{95}\right)$.

The first index evaluates the harmonic distortion level in terms of the RMS value of the individual voltage harmonic components. The second index is the 95 percentile of the THDV , defined as:

$$
T H D_{V}=\frac{\sqrt{\sum_{h=2}^{H} V_{h}^{2}}}{V_{1}} \cdot 100
$$

where $\mathrm{H}$ is the maximum value of the harmonic order, $\mathrm{V}_{\mathrm{h}}$ is the RMS value of the voltage harmonic of order $h$ and $\mathrm{V}_{1}$ is the RMS value of the voltage at fundamental frequency.

The following system indices are considered:
- the 95 percentile of the System Voltage harmonic amplitude $\left(\mathrm{V}_{95}^{\mathrm{h}}\right)$;

- the 95 percentile of the System Voltage Total Harmonic Distortion (STHDV 95 );

- the System Average Voltage Total Harmonic Distortion Variation (SATHDV).

The $\mathrm{V}_{95}^{\mathrm{h}}$ index is defined as the 95 percentile value derived from a weighted distribution which is obtained computing, for each site, the relative frequencies of the voltage harmonics and weighting them with the ratio between the connected kVA served from the system segment and the total connected kVA served from the system. The STHDV 95 and SATHDV indices are, respectively, defined as the 95 percentile value and the mean value of a weighted distribution obtained computing, for each site, the relative frequencies of the Voltage Total Harmonic Distortion THDV and weighting them with the ratio between the connected $\mathrm{kVA}$ served from the system segment and the total connected $\mathrm{kVA}$ served from the system.

3) Voltage unbalance

The considered site index $\left(\mathrm{K}_{\mathrm{d} 95}\right)$ is the 95 percentile of the ratio $K_{d}$ between the RMS values of the supply voltage negative phase sequence component $V_{n}$ and the positive phase sequence component $V_{p}$ at fundamental frequency referred to a single bus and defined as:

$$
K_{d}=\frac{V_{n}}{V_{p}} \cdot 100 .
$$

The site index $\mathrm{K}_{\mathrm{d} 95}$ can be extended to the system index $\mathrm{SK}_{\mathrm{d} 95}$ in a similar way to the system indices for waveform distortions.

4) Voltage fluctuations

As well known, the following indices are usually considered to characterize voltage fluctuations:

- the short term (10 minutes) severity index $\mathrm{P}_{\mathrm{st}}$;

- the long term (2 hours) severity index $\mathrm{P}_{\mathrm{lt}}$.

For calculating $\mathrm{P}_{\mathrm{st}}$ index values, the flickermeter with characteristics specified in the IEC 61000-4-15 is used. The long term severity index $\mathrm{P}_{\mathrm{lt}}$ values are calculated by using a sequence of 12 values of the $\mathrm{P}_{\mathrm{st}}$ over a time range of 2 hours. The 95 percentile derived by the probability density function (pdf) of $\mathrm{P}_{\mathrm{st}}$ has been used as site index.

5) Voltage sag

The following site indices are considered:

- the 95 percentile of the Voltage Dip Amplitude (VDA 95$)$;

- $\quad$ the Average Voltage Dip Amplitude (AVDA).

The first index, referred to a single bus, is defined as the 95 percentile of the remaining voltage RMS value (less than the $90 \%$ of the nominal value). The second index is defined as the mean value of the voltage dip amplitude value evaluated at a single bus.

The system indices are:

- the 95 percentile of the System Voltage Dip Amplitude (SVDA 95$)$;

- the System Average Voltage Dip Amplitude (SAVDA), 
which are the $\mathrm{VDA}_{95}$ and AVDA extended to the entire system.

\section{B. New Indices}

Let us consider one of the above mentioned traditional PQ index, $X$, and let us assume that $X_{D G}$ is the value of index $\mathrm{X}$ in presence of dispersed generation whereas $\mathrm{X}_{\mathrm{NO} \_ \text {DG }}$ is the value of index $\mathrm{X}$ in absence of dispersed generation.

Using these assumptions, it defines the percentage variation of the index $\left(\mathrm{X}_{\mathrm{V} \%}\right)$ due to the DG introduction with respect to the value without DG:

$$
X_{V \%}=\frac{X_{N O_{-} D G}-X_{D G}}{X_{N O \_D G}} \cdot 100
$$

The index reported in relationship (3) allows to quantify the improvement or deterioration of PQ levels of the electrical service related to the installations of new generation units. Moreover, it should be noted that this index can be calculated for both PQ "single site indices" and "system indices".

\section{DG and Loads Uncertainties Characterization}

DG can be sourced from different types of primary energy sources (e.g. wind, solar, fossil fuels, water, biomass, etc.). From the point of view of the power output evaluation, DG can generally be grouped into two main types: those which have an output dependent on a programmable energy primary source and can be dispatched (e.g. gas turbine units) and those which have an output dependent on a variable energy primary source and could not be dispatched (e.g. wind farm, photovoltaic system, small-scale hydro).

The former type is modeled using deterministic approaches, constraining the DG power output into a fixed set of values which have no variability (e.g. DG rated power).

The latter type is more difficult to deal with because of the stochastic behavior of the energy primary source. Then, DG has to be modeled using probabilistic approaches, which are based on analytical or simulation techniques. In the field of Power Quality level assessment, probability density functions are usually used to characterize random input variables (wind speed and solar irradiance) and analytical or Monte Carlo simulation procedures are applied to obtain the statistical characterization of the output random variables.

In this paper, only the case of Wind Farms (WFs) is considered. In particular, the wind speed is modeled by the record of available data. Each Wind Turbine Generator (WTG) is modeled by using its control characteristic, which determines the power output of the conversion devices as a function of wind speed data. By applying the control characteristic of each WTG to the wind speed sample, the corresponding sequence of the WTG power output is evaluated and, then, the corresponding probability density function can be obtained. In the case of a WF composed of more than one WTG, the outputs of WTGs belonging at the same WF are appropriately aggregated.
With reference to the customer demand, typically, loads are modeled by normal distributions whose mean value and relative variance are constant. This representation is used when the typical time horizon is the year. More detailed representations (hourly or daily time horizons) can be performed involving an increase of the computational effort.

\section{Application}

A tool for the calculation of the indices reported in Section 2 has been developed by using ${ }^{\circledR}$ DigSilent Power Factory software. This tool allows the evaluation of both single site and system indices by means of Monte Carlo simulations. The probabilistic approach allows to take into account the stochastic behavior of the customer demands and the WTGs power outputs. Several applications on a MV 120-bus distribution network are performed in order to show the usefulness of these indices. The distribution network is the one considered in [6] in which the optimally allocation of the custom power devices has been analyzed.

The MV distribution system includes a rural and an urban network, whose configurations are reported in Fig. 1 a) and Fig. 1 b), respectively.

DG includes 5 WFs, connected to busbars \#63, 116, 119, 109,58 , and 4 gas turbine units, referred in the following as TGs and connected to busbars \#67, 26, 34 ,35 (see Fig. 1 ). Each WF is composed of 1 WTG with rated power equal to $1 \mathrm{MW}$; each WTG can be equipped with double fed induction generator or with induction generator without electronic interface. All TGs are rated for 3.75 MVA with a generation of active and reactive power equal to 2.5 MW and 0.2 MVAr, respectively.

Finally, there are linear loads and 2 DC loads supplied by AC/DC six pulse converters connected at buses \#20 and 21 of the urban network (Fig1 b).

The WFs have been modeled as described in Section 3. Active and reactive powers of all loads have been modeled as Gaussian random variables whose mean values are reported in Table A1 of Appendix; their standard deviations in all conditions are assumed to be $10 \%$ of the mean values.

Several applications have been performed; for the sake of conciseness only four cases are reported in the following:

a) Case 1: distribution network without DG units.

b) Case 2: distribution network with all DG units and WTGs equipped with double fed induction generators (DFIG).

c) Case 3: distribution network with a level of DG penetration equal to 30\%; it has been realized using 4 WTGs equipped with DFIG, connected to busbars \#63, 116, 119, 109 and using 2 TGs connected to busbars \#34, 35.

d) Case 4: distribution network with all DG units and WTGs equipped with induction generators without electronic interface.

In the following, for the sake of conciseness, site and system indices related only to the slow voltage variations and waveform distortions are reported. 


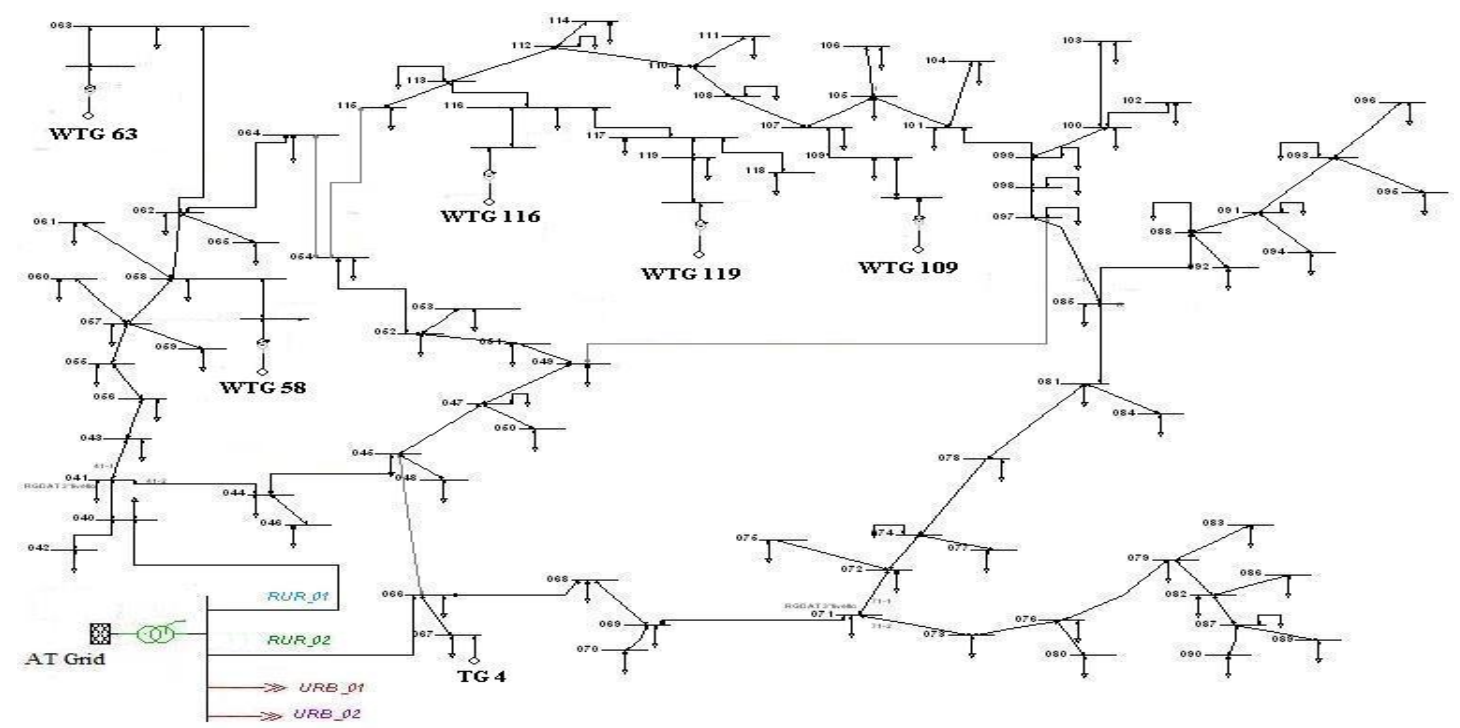

(a)

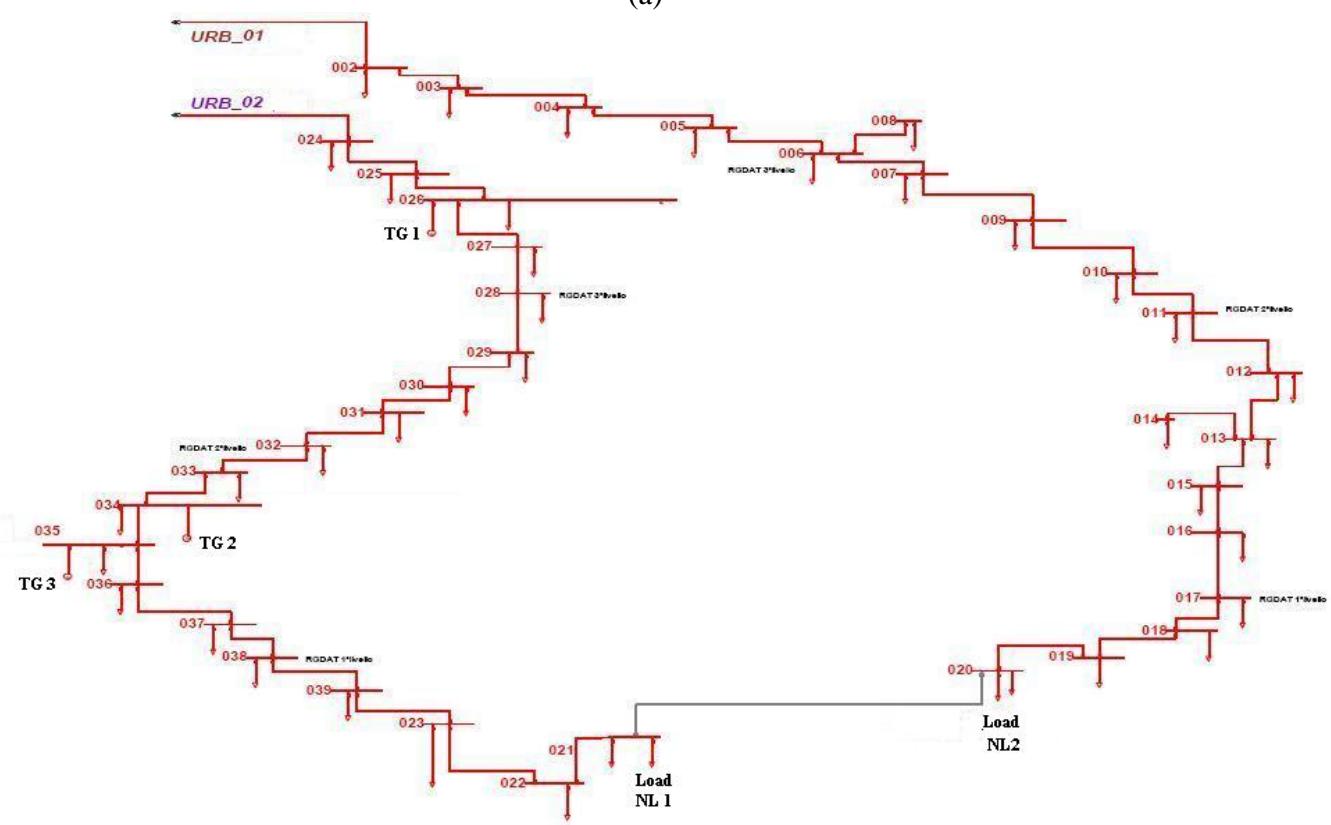

(b)

Fig. 1 - The distribution system: (a) rural network and (b) urban network.

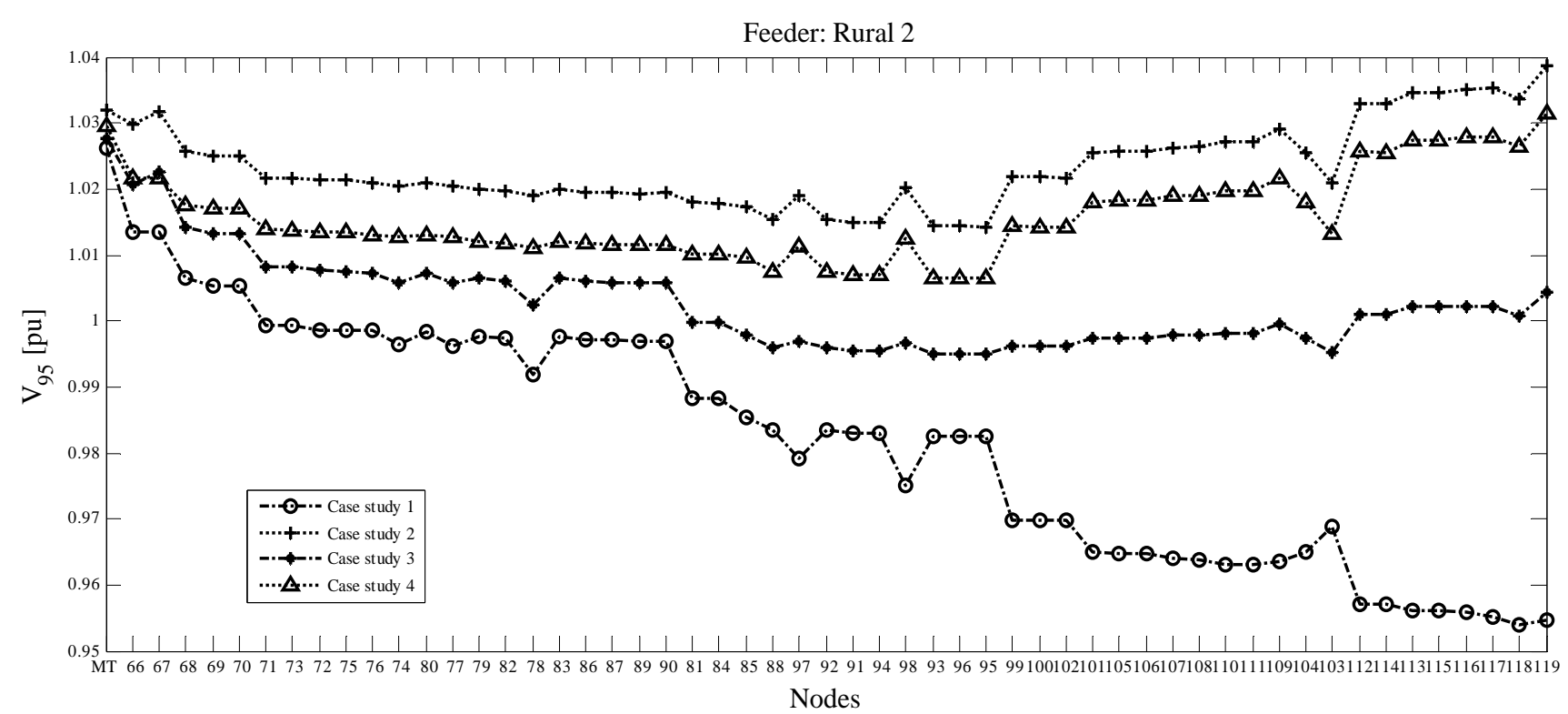

Fig. 2 - Feeder 2 of rural network: 95 percentile of the supply voltage RMS. 


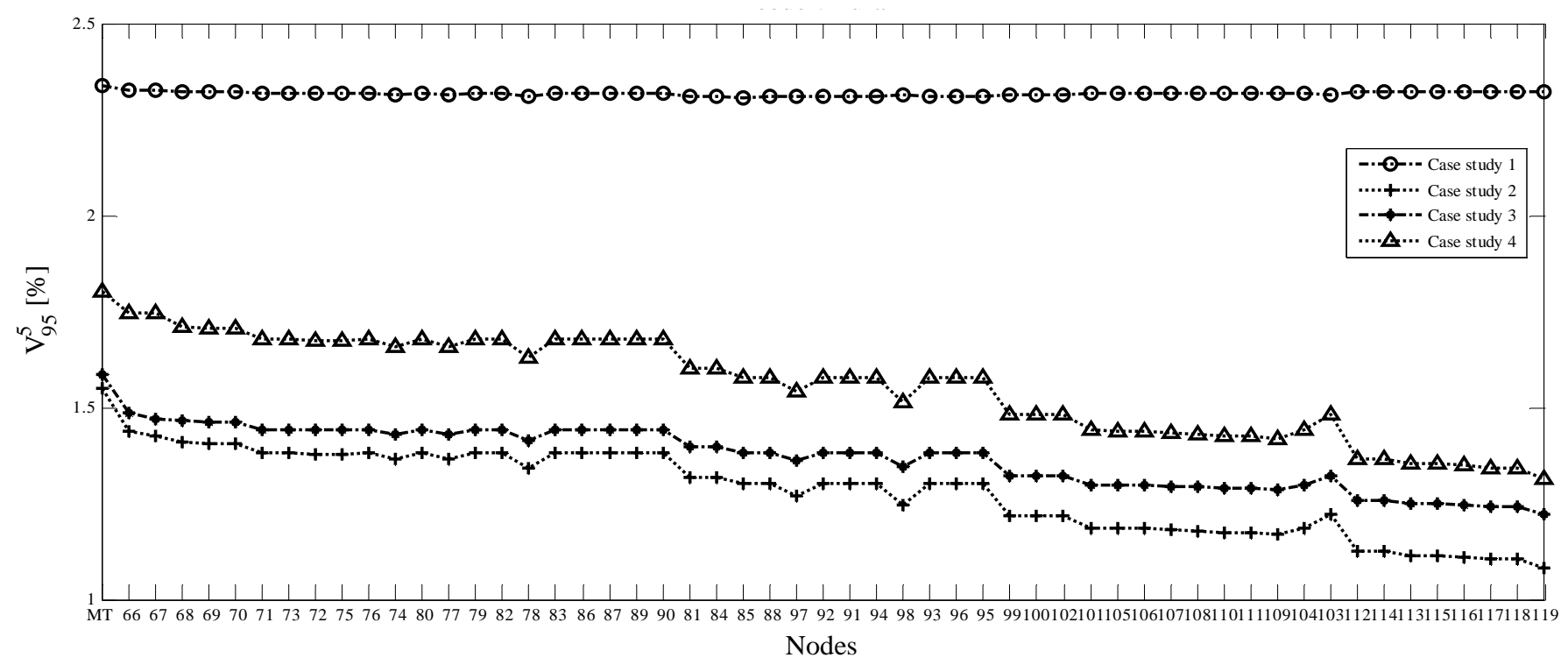

Fig. 3 - Feeder 2 of rural network: 95 percentile of the fifth harmonic voltage amplitude

\section{A. Slow voltage variations}

With reference to the site index, as an example, in Fig. 2 the 95 percentile of the supply voltage RMS pdf (related to the feeder 2 of rural network) obtained in the above case studies are reported. From the analysis of Fig. 2 it clearly appears the advantage in terms of slow voltage variations site indices due to the presence of GD units (case studies from 2 to 4). It should be also noted that WTGs with DFIG configuration (case study 2) furnish better performance with respect to the WTGs simulated without electronic interface (case study 4).

With reference to the system index, the average value of the site indices results $\mathrm{SV}_{95}=1.013$. Finally, the percentage variations of the $\mathrm{SV}_{95}$ index obtained applying relation (3) are $-2.44 \%,-1.19 \%$ and $-1.87 \%$ confirming the improvement of the electrical service due to installations of new generation units (case studies from 2 to 4$)$.

\section{B. Waveform distortions}

With reference to the site index, let us consider firstly the 95 percentile of the voltage harmonic amplitude. In Fig. 3 the 95 percentile of fifth harmonic voltage $\left(V_{95}^{5}\right)$ related to the feeder 2 of rural network nodes are reported whereas Fig. 4 shows the same quantities but referred to feeder 2 of the urban network. From the analysis of Figs. 3 and 4, it clearly appears the improvement in terms of $\mathrm{V}_{95}^{5}$ obtained from the installation of GD units (case studies from 2 to 4 ). This improvement is mainly due to the increment of the voltage RMS values at fundamental frequency.

The percentage variation of the site index $V_{95}^{5}$ can be calculated applying relation (3); Fig. 5 shows the results related to feeder 2 of urban network and evidences, once again, the improvement of the electrical service due to installations of new generation units in case studies from 2 to 4 .

Now, let us consider the 95 percentile of the Voltage Total Harmonic Distortion ( $\mathrm{THDV}_{95}$ ) site index. In Fig. 6 $\mathrm{THDV}_{95}$ related to feeder 2 of the rural network nodes are reported while Fig. 7 shows the same quantities but referred to feeder 2 of the urban network. From the analysis of Fig. 6 it appears that only in case study 4 there is an improvement of $\mathrm{THDV}_{95}$ at all nodes; on the other hand, in case studies 2 and $3 \mathrm{THDV}_{95}$ can deteriorate in the nodes nearest to HV/MV station. The same considerations can be made for nodes of feeder 2 of urban network (see Fig. 7).

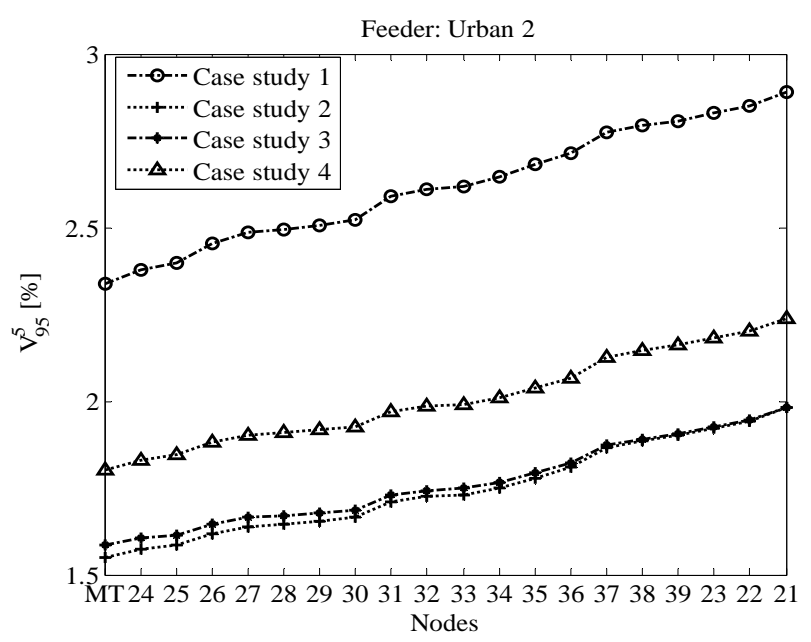

Fig. 4 - Feeder 2 of urban network: 95 percentile of the fifth harmonic voltage amplitude

Feeder: Urban 2

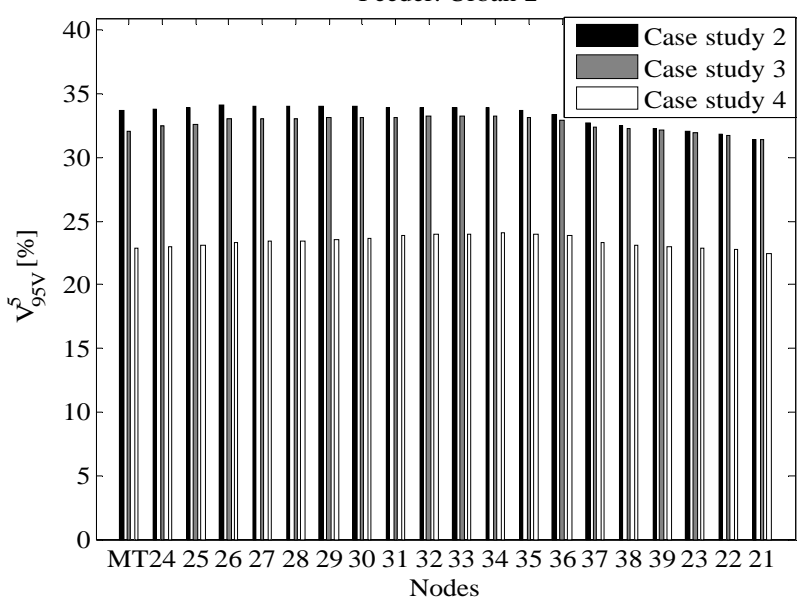

Fig. 5 - Feeder 2 of urban network: percentage variation of 95 percentile fifth voltage harmonic amplitude. 
Feeder: Rural 2

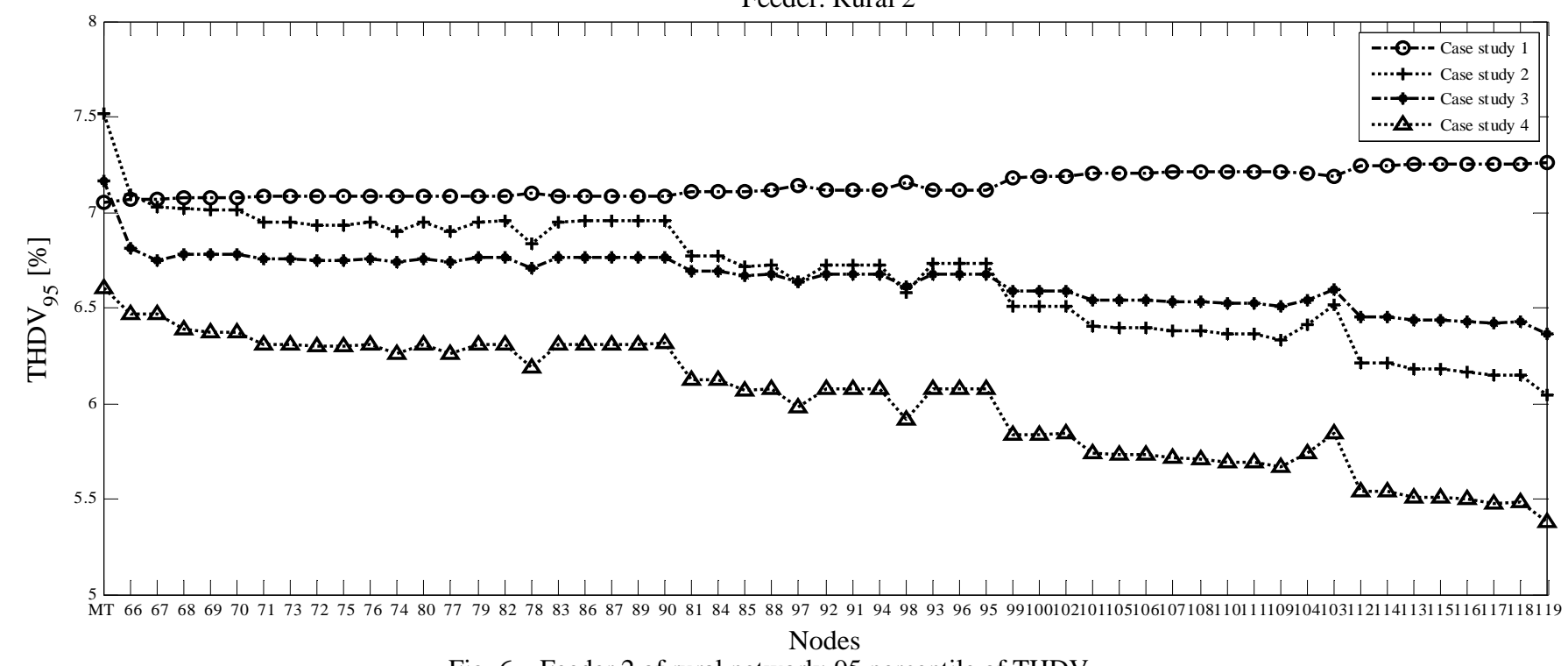

Fig. 6 - Feeder 2 of rural network: 95 percentile of THDV

The site index percentage variation of $\mathrm{THDV}_{95}$ can be calculated applying relation (3); Fig. 8 shows the results related to feeder 2 of the urban network and evidences the improvement and deterioration of the electrical service due to installations of new generation units (case studies from 2 to 4 ).

With reference to the system indices, in Table I we report the values of the indices $\mathrm{SV}_{95}^{5}$, STHDV 95 and SATHDV while Table II shows the percentage variation of the same indices calculated applying relation (3).

From the analysis of Tables I and II it appears that the installations of new GD units can cause both improvement and deterioration of the PQ in terms of voltage distortions. In particular, in case studies 3 and 4 only the improvements are observed; on the other hand, the installation of all DG units with WTGs characterized by DFIG configurations provides a deterioration of the voltage distortion in terms of STHDV S5 $_{95}$ and SATHDV.

\section{Conclusion}

The penetration of dispersed generation (DG) influences the Power Quality levels in the distribution networks. An accurate assessment of PQ disturbances in presence of DG can be effected by using adequate probabilistic indices which properly quantify the random nature of the disturbances.

In this paper, a tool for the calculation of slow voltage variations, waveform distortions, unbalances, voltage fluctuations and voltage sag probabilistic indices has been developed by using ${ }^{\circledR}$ DigSilent Power Factory software.

Table I. - $\mathrm{SV}_{95}^{5}$, STHDV 95 and SATHDV system indices

\begin{tabular}{|c|c|c|c|c|}
\hline Indices & $\begin{array}{c}\text { Case } \\
\text { study 1 }\end{array}$ & $\begin{array}{c}\text { Case } \\
\text { study 2 }\end{array}$ & $\begin{array}{c}\text { Case } \\
\text { study 3 }\end{array}$ & $\begin{array}{c}\text { Case } \\
\text { study 4 }\end{array}$ \\
\hline $\mathrm{SV}_{95}^{5}[\%]$ & 2.69 & 1.87 & 1.92 & 2.12 \\
\hline STHDV $_{95}[\%]$ & 7.35 & 7.60 & 7.26 & 6.74 \\
\hline SATHDV [\%] & 6.55 & 6.70 & 6.41 & 5.96 \\
\hline
\end{tabular}

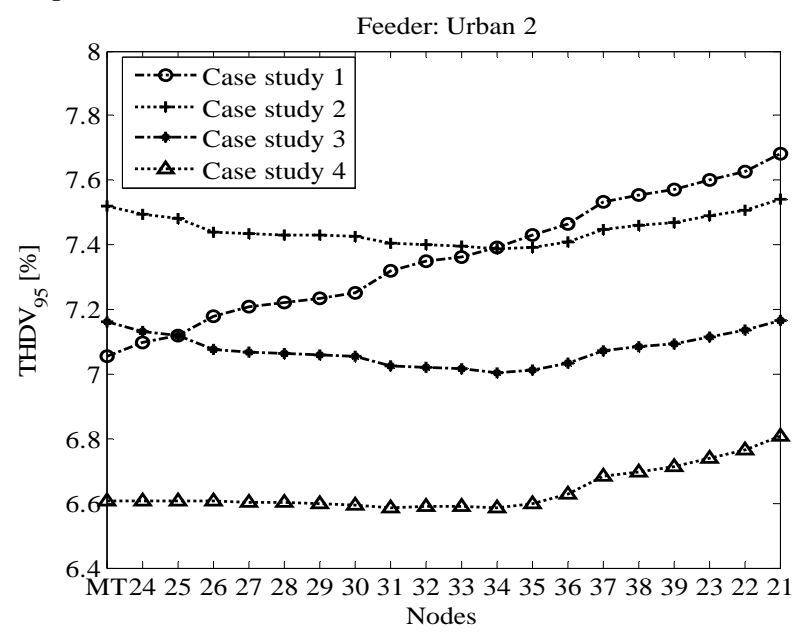

Fig. 7 - Feeder 2 of urban network: 95 percentile of THDV

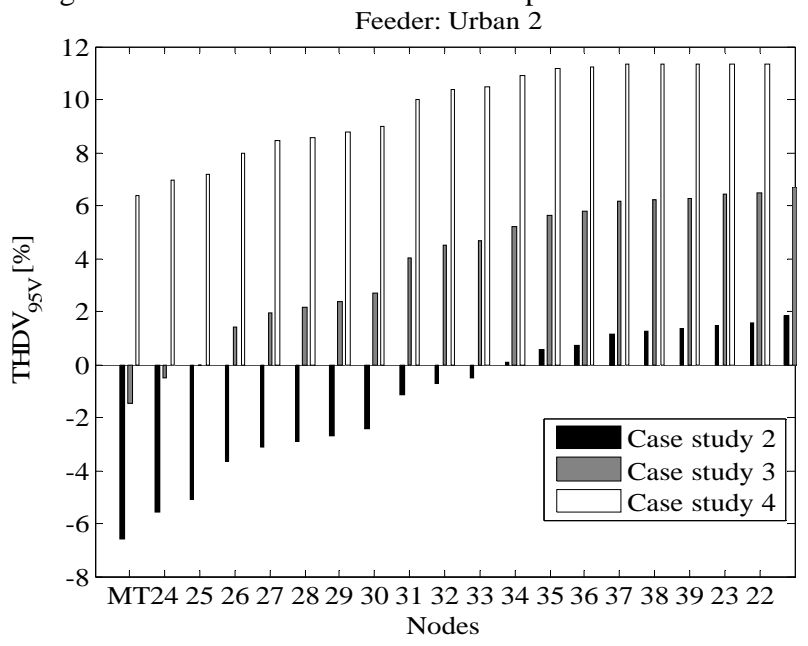

Fig. 8 - Feeder 2 of urban network: percentage variation of $\mathrm{THDV}_{95}$

Table II. - Percentage variation of $\mathrm{SV}_{95}^{5}$, $\mathrm{STHDV}_{95}$ and

\begin{tabular}{|c|c|c|c|}
\hline \multicolumn{4}{|c}{ SATHDV } \\
\hline Indices & $\begin{array}{c}\text { Case } \\
\text { study 2 }\end{array}$ & $\begin{array}{c}\text { Case } \\
\text { study 3 }\end{array}$ & $\begin{array}{c}\text { Case } \\
\text { study 4 }\end{array}$ \\
\hline SV $_{95 \mathrm{~V}}^{5}[\%]$ & 30.54 & 28.63 & 21.27 \\
\hline STHDV $_{95 \mathrm{~V}}[\%]$ & -3.33 & 1.23 & 8.33 \\
\hline SATHDV $_{\mathrm{V}}[\%]$ & -2.35 & 2.11 & 9.03 \\
\hline
\end{tabular}


Numerical simulations based on a Monte Carlo procedure have been performed on a 120-bus distribution network whose DG units are wind generators and gas turbine systems. Numerical applications allowed the calculation of both traditional site and system indices as well as new indices which identify the improvement or deterioration of PQ levels of the electrical service due to the installation of new generation units. The results show both improvement and deterioration of the electrical service in terms of different PQ disturbances.

\section{References}

[1] N. Jenkins, R. Allan, P. Crossley, D. Kirschen, G. Strbac: "Embedded Generation”, IEE Publisher, London, 2000

[2] P. Caramia, G. Carpinelli, A. Russo, P. Verde: “Some Considerations on Single Site and System Probabilistic Harmonic Indices for Distribution Networks", Proc. 2003 IEEE Power Engineering Society General Meeting, Toronto, Ontario (Canada), July 2003

[3] C. Di Perna, G. Olguin, P. Verde, M.H.J. Bollen: "On probabilistic system indices for voltage dips”, International Conference on Probabilistic Methods Applied to Power Systems (PMAPS), Ames (USA), September 2004

[4] P. Caramia, G. Carpinelli, A. Russo, P. Verde: “New system power quality indices for distribution networks in presence of embedded generation”, CIGRE Symposium on "Power Systems with dispersed generation”, Athens (Greece), April 2005

[5] G.Carpinelli, G.Celli, F.Pilo, A.Russo: "Embedded generation planning under uncertainty including power quality issues", European Transactions on Electrical Power Vol.13, N.6, December 2003, pp 381-389

[6] F. Pilo, G. Pisano, G. G. Soma: “Optimal Placement of Custom Power Devices to Mitigate Voltage Dips in Distribution Networks", 13th International Conference on Harmonics and Quality of Power (ICHQP) 2008. Wollongong (Australia), September/October 2008

\section{Appendix}

\author{
Table A1
}

Active and reactive mean values of rural network (a) and urban network (b) load powers

(a)

\begin{tabular}{|c|c|c|c|c|c|}
\hline Nodes & $\begin{array}{c}\mathrm{P} \\
{[\mathrm{kW}]}\end{array}$ & $\begin{array}{c}\mathrm{Q} \\
{[\mathrm{kVAr}]}\end{array}$ & Nodes & $\begin{array}{c}\mathrm{P} \\
{[\mathrm{kW}]}\end{array}$ & $\begin{array}{c}\mathrm{Q} \\
{[\mathrm{kVAr}]}\end{array}$ \\
\hline $\mathbf{4 0}$ & 84.00 & 40.68 & $\mathbf{8 0}$ & 72.00 & 34.87 \\
\hline $\mathbf{4 1}$ & 60.07 & 29.09 & $\mathbf{8 1}$ & 93.62 & 45.34 \\
\hline $\mathbf{4 2}$ & 72.00 & 34.87 & $\mathbf{8 2}$ & 60.07 & 29.09 \\
\hline $\mathbf{4 3}$ & 72.00 & 34.87 & $\mathbf{8 3}$ & 28.38 & 13.75 \\
\hline $\mathbf{4 4}$ & 84.00 & 40.68 & $\mathbf{8 4}$ & 128.00 & 61.99 \\
\hline $\mathbf{4 5}$ & 84.00 & 40.68 & $\mathbf{8 5}$ & 21.26 & 10.30 \\
\hline $\mathbf{4 6}$ & 72.00 & 34.87 & $\mathbf{8 6}$ & 86.40 & 41.85 \\
\hline $\mathbf{4 7}$ & 93.62 & 45.34 & $\mathbf{8 7}$ & 112.34 & 54.41 \\
\hline $\mathbf{4 8}$ & 128.00 & 61.99 & $\mathbf{8 8}$ & 72.08 & 34.91 \\
\hline $\mathbf{4 9}$ & 17.71 & 8.58 & $\mathbf{8 9}$ & 86.40 & 41.85 \\
\hline $\mathbf{5 0}$ & 72.00 & 34.87 & $\mathbf{9 0}$ & 14.40 & 6.97 \\
\hline $\mathbf{5 1}$ & 104.00 & 50.37 & $\mathbf{9 1}$ & 124.80 & 60.44 \\
\hline $\mathbf{5 2}$ & 60.07 & 29.09 & $\mathbf{9 2}$ & 6.59 & 3.19 \\
\hline $\mathbf{5 3}$ & 72.00 & 34.87 & $\mathbf{9 3}$ & 112.34 & 54.41 \\
\hline $\mathbf{5 4}$ & 128.00 & 61.99 & $\mathbf{9 4}$ & 153.60 & 74.39 \\
\hline $\mathbf{5 5}$ & 60.07 & 29.09 & $\mathbf{9 5}$ & 72.08 & 34.91 \\
\hline $\mathbf{5 6}$ & 11.39 & 5.52 & $\mathbf{9 6}$ & 6.59 & 3.19 \\
\hline $\mathbf{5 7}$ & 93.62 & 45.34 & $\mathbf{9 7}$ & 27.77 & 13.45 \\
\hline $\mathbf{5 8}$ & 104.00 & 50.37 & $\mathbf{9 8}$ & 44.45 & 21.53 \\
\hline $\mathbf{5 9}$ & 11.39 & 5.52 & $\mathbf{9 9}$ & 100.80 & 48.82 \\
\hline $\mathbf{6 0}$ & 244.14 & 118.24 & $\mathbf{1 0 0}$ & 86.40 & 41.85 \\
\hline $\mathbf{6 1}$ & 11.39 & 5.52 & $\mathbf{1 0 1}$ & 34.06 & 16.49 \\
\hline $\mathbf{6 2}$ & 60.07 & 29.09 & $\mathbf{1 0 2}$ & 72.08 & 34.91 \\
\hline $\mathbf{6 3}$ & 5.72 & 2.77 & $\mathbf{1 0 3}$ & 100.80 & 48.82 \\
\hline $\mathbf{6 4}$ & 244.14 & 118.24 & $\mathbf{1 0 4}$ & 8.53 & 4.13 \\
\hline $\mathbf{6 5}$ & 11.39 & 5.52 & $\mathbf{1 0 5}$ & 86.40 & 41.85 \\
\hline $\mathbf{6 6}$ & 84.00 & 40.68 & $\mathbf{1 0 6}$ & 72.08 & 34.91 \\
\hline $\mathbf{6 7}$ & 72.00 & 34.87 & $\mathbf{1 0 7}$ & 100.80 & 48.82 \\
\hline $\mathbf{6 8}$ & 17.72 & 8.58 & $\mathbf{1 0 8}$ & 86.40 & 41.85 \\
\hline $\mathbf{6 9}$ & 104.00 & 50.37 & $\mathbf{1 0 9}$ & 112.34 & 54.41 \\
\hline $\mathbf{7 0}$ & 72.00 & 34.87 & $\mathbf{1 1 0}$ & 34.06 & 16.49 \\
\hline $\mathbf{7 1}$ & 60.07 & 29.09 & $\mathbf{1 1 1}$ & 8.53 & 4.13 \\
\hline $\mathbf{7 2}$ & 60.07 & 29.09 & $\mathbf{1 1 2}$ & 124.80 & 60.44 \\
\hline $\mathbf{7 3}$ & 93.62 & 45.34 & $\mathbf{1 1 3}$ & 13.67 & 6.62 \\
\hline $\mathbf{7 4}$ & 60.07 & 29.09 & $\mathbf{1 1 4}$ & 86.40 & 41.85 \\
\hline $\mathbf{7 5}$ & 72.00 & 34.87 & $\mathbf{1 1 5}$ & 8.53 & 4.13 \\
\hline $\mathbf{7 6}$ & 84.00 & 40.68 & $\mathbf{1 1 6}$ & 13.67 & 6.62 \\
\hline $\mathbf{7 7}$ & 72.00 & 34.87 & $\mathbf{1 1 7}$ & 72.08 & 34.91 \\
\hline $\mathbf{7 8}$ & 265.72 & 128.69 & $\mathbf{1 1 8}$ & 318.86 & 154.43 \\
\hline $\mathbf{7 9}$ & 84.00 & 40.68 & $\mathbf{1 1 9}$ & 100.80 & 48.82 \\
\hline
\end{tabular}

(b)

\begin{tabular}{|c|c|c|c|c|c|}
\hline Nodes & $\begin{array}{c}\mathrm{P} \\
{[\mathrm{kW}]}\end{array}$ & $\begin{array}{c}\mathrm{Q} \\
{[\mathrm{kVAr}]}\end{array}$ & Nodes & $\begin{array}{c}\mathrm{P} \\
{[\mathrm{kW}]}\end{array}$ & $\begin{array}{c}\mathrm{Q} \\
{[\mathrm{kVAr}]}\end{array}$ \\
\hline $\mathbf{2}$ & 640.00 & 640.19 & $\mathbf{2 1}$ & 2620.0 & 120.04 \\
\hline $\mathbf{3}$ & 150.00 & 71.37 & $\mathbf{2 2}$ & 200.00 & 200.06 \\
\hline $\mathbf{4}$ & 89.00 & 41.84 & $\mathbf{2 3}$ & 220.00 & 220.07 \\
\hline $\mathbf{5}$ & 310.00 & 310.09 & $\mathbf{2 4}$ & 410.00 & 410.12 \\
\hline $\mathbf{6}$ & 290.00 & 290.09 & $\mathbf{2 5}$ & 730.00 & 730.22 \\
\hline $\mathbf{7}$ & 470.00 & 470.14 & $\mathbf{2 6}$ & 5.50 & 5.50 \\
\hline $\mathbf{8}$ & 270.00 & 126.14 & $\mathbf{2 7}$ & 5.50 & 5.50 \\
\hline $\mathbf{9}$ & 390.00 & 192.19 & $\mathbf{2 8}$ & 360.00 & 360.11 \\
\hline $\mathbf{1 0}$ & 301.00 & 147.48 & $\mathbf{2 9}$ & 460.00 & 460.14 \\
\hline $\mathbf{1 1}$ & 710.00 & 331.71 & $\mathbf{3 0}$ & 400.00 & 400.12 \\
\hline $\mathbf{1 2}$ & 360.00 & 171.29 & $\mathbf{3 1}$ & 270.00 & 270.08 \\
\hline $\mathbf{1 3}$ & 460.00 & 226.68 & $\mathbf{3 2}$ & 950.00 & 465.47 \\
\hline $\mathbf{1 4}$ & 10.00 & 4.87 & $\mathbf{3 3}$ & 710.00 & 710.21 \\
\hline $\mathbf{1 5}$ & 20.00 & 9.86 & $\mathbf{3 4}$ & 600.00 & 600.18 \\
\hline $\mathbf{1 6}$ & 30.00 & 14.27 & $\mathbf{3 5}$ & 75.00 & 36.32 \\
\hline $\mathbf{1 7}$ & 355.00 & 168.91 & $\mathbf{3 6}$ & 50.00 & 24.50 \\
\hline $\mathbf{1 8}$ & 500.00 & 500.15 & $\mathbf{3 7}$ & 30.00 & 14.36 \\
\hline $\mathbf{1 9}$ & 450.00 & 450.14 & $\mathbf{3 8}$ & 10.00 & 10.00 \\
\hline $\mathbf{2 0}$ & 2360.0 & 360.11 & $\mathbf{3 9}$ & 130.00 & 62.22 \\
\hline
\end{tabular}

